\title{
Responses of Endothelial Cells from Different Vessels to Inflammatory Cytokines and Shear Stress: Evidence for the Pliability of Endothelial Phenotype
}

\author{
N. Thin Luu Mahbub Rahman Phil C. Stone G. Ed Rainger Gerard B. Nash \\ Centre for Cardiovascular Sciences, The University of Birmingham, Birmingham, UK
}

\section{Key Words}

Endothelium • Inflammation · Cytokines · Shear stress ·

Leukocytes · Adhesion

\begin{abstract}
Background/Aims: Local haemodynamic and stromal microenvironments may determine the phenotype of endothelial cells $(E C)$ and regulate their inflammatory responses. Methods: We compared neutrophil recruitment by EC from human umbilical veins (HUVEC) or arteries (HUAEC) or from human coronary arteries (HCAEC) after 'static' culture or exposure to shear stress ( $2 \mathrm{~Pa}$ for $24 \mathrm{~h}$ ) and treatment with tumour necrosis factor- $\alpha$ (TNF- $\alpha$ ) or interleukin-1 $\beta$ (IL-1 $\beta$ ). $\boldsymbol{R e}$ sults: Static cultures of each type of EC recruited flowing neutrophils efficiently after treatment with TNF- $\alpha$ or IL-1 3 ; differences in culture media caused minor variations. After shear conditioning, the response of HUVEC to TNF- $\alpha$ (but not IL-1 $\beta$ ) was much reduced, while the responses of HUAEC and HCAEC to both cytokines were reduced. However, swapping the culture media suggested that the differences in the shear response arose largely from medium constituents, particularly basic fibroblast growth factor. When gene expression profiles for HUVEC were examined immediately after isolation, after 5 days in static culture and after re-exposure to shear, variations in gene expression were only par-
\end{abstract}

tially attributable to the effects of changes in shear stress. Conclusions: The behaviour of cultured EC may depend as much on the physico-chemical culture conditions as on their origins. The EC phenotype appears to be highly pliable, with environmental factors, such as shear stress and growth factors, modifying responses in an inter-linked manner.

Copyright $\odot 2010$ S. Karger AG, Basel

\section{Introduction}

In the circulation, endothelial cells (EC) are continually exposed to frictional forces exerted by flowing blood (i.e. wall shear stress). Studies in vitro and in vivo have shown that the structure of EC and each of their functions (in haemostasis, regulation of vascular tone, angiogenesis and the control of movement of solutes and leukocytes between the vascular compartment and tissue) are modulated by the applied shear stress [1-3]. The magnitude of shear stress varies throughout the vascular tree (e.g., wall shear stress is approx. 1-5 $\mathrm{Pa}$ in the arterial circulation, falling to $0.1-2 \mathrm{~Pa}$ on the venous side) and between organs $[4,5]$. In arteries, pulsatility is imposed by the cardiac cycle, while curvatures, bifurcations and vessel tortuosity lead to areas of flow separation and recirculation. In general, it appears that EC may develop a

\section{KARGER}

Fax +4161306 1234 E-Mail karger@karger.ch www.karger.com (c) 2010 S. Karger AG, Basel

$1018-1172 / 10 / 0475-0451 \$ 26.00 / 0$

Accessible online at:

www.karger.com/jvr
Prof. Gerard B. Nash

School of Clinical and Experimental Medicine

The Medical School, The University of Birmingham

Birmingham B15 2TT (UK)

Tel. +44 121414 3670, Fax +44 121414 6919, E-Mail g.nash@bham.ac.uk 
stable phenotype which depends on local shear conditions and may also respond acutely to changes in flow. The endothelial phenotype will also depend on the underlying stromal environment $[6,7]$. Although the critical stromal factors controlling function are not so well defined, we and others have shown, for example, that growth factors and cytokines from smooth muscle cells and fibroblasts modulate inflammatory responses at least [8-10]. The combined effects of stromal and haemodynamic factors have been studied only in rare cases [9].

EC contribute actively to inflammatory responses by controlling the recruitment of leukocytes in response to locally released cytokines [such as tumour necrosis factor- $\alpha$ (TNF- $\alpha$ ) and interleukin-1 $\beta$ (IL-1 $\beta)]$ [11-13]. These agonists cause up-regulation of the surface expression of endothelial adhesion receptors such as selectins and vascular adhesion molecule-1 (VCAM-1), which are required for the capture of flowing leukocytes. In addition, they induce the presentation of chemokines, whose ligation by G-protein-coupled receptors on leukocytes leads to activation of $\beta 2$-integrins and stimulation of cell motility. These enable firm binding to inter-cellular adhesion molecule-1 (ICAM-1) and subsequent migration over and through the endothelium, respectively. Previous studies, including our own, have shown that exposure of EC to shear stress in vitro reduces the response to TNF- $\alpha$ compared to static cultures [14-16]. Neutrophil adhesion to EC was progressively reduced, the longer EC were cultured under flow before exposure to TNF- $\alpha$ and the higher the shear stress that was applied [16]. This downregulation was linked to inhibition of TNF- $\alpha$ induction of genes for adhesion receptors (including E-selectin) and chemokines $[16,17]$. Prolonged exposure to shear stress also inhibited TNF- $\alpha$-induced activation of mitogen-activated protein kinases and up-regulation of VCAM-1 [18]. Perhaps surprisingly, we found that such shear conditioning did not reduce the pro-adhesive response of EC to IL-1 $\beta$ [13].

The foregoing raises questions regarding the local environmental control of leukocyte recruitment and the differences between the abilities of EC from different sites to support adhesion and migration. Leukocyte recruitment during inflammation occurs almost exclusively in post-capillary venules $[19,20]$, rarely in arteries, and different endothelial adhesion receptors operate in organs such as the lungs and liver compared to tissue such as skin or muscle [21-24]. Wall shear stress differs between these sites, and while this will directly affect adhesion from flow, the endothelial phenotype and adhesion receptors expressed also differ. It is uncertain how stable the imprinted endothelial phenotype is, but culture in vitro will inevitably impose different environmental conditions and is typically carried out without flow. Studies of leukocyte recruitment in vitro have used EC from human umbilical vein (HUVEC) most frequently, although some studies have also used EC from umbilical artery (HUAEC), saphenous vein (SVEC), liver, lung, skin or coronary artery (HCAEC) [25-30]. However, comparative studies incorporating the effects of exposure to different growth media and shear stress are rare and have not used flow-based assays of leukocyte recruitment. We thus tested whether cultured HUVEC, HUAEC and HCAEC differed in their ability to support adhesion of flowing neutrophils in response to TNF- $\alpha$ or IL-1 $\beta$ and whether this depended on the culture media (e.g. containing different growth factors) and conditioning by shear stress. In this way, we aimed to find out whether EC from different sites retained different responses in vitro and, more generally, how pliable endothelial phenotypes are in response to environmental cues such as shear stress and growth factors.

\section{Materials and Methods}

\section{Culture of EC under Static or Flow Conditions}

HUVEC were isolated using collagenase as previously described [31] and maintained in one of the media listed in table 1. HUAEC were isolated from umbilical arteries by the same method and cultured in one of the media shown in table 1. HCAEC were purchased from Promocell GmbH (Heidelberg, Germany) and cultured in the manufacturer's recommended medium, designated 'HCAEC' medium (table 1). Notable ingredients that varied between the media were human recombinant epidermal growth factor (EGF), human, recombinant basic fibroblast growth factor (bFGF) and EC growth supplement/heparin.

In some experiments, HUVEC were immediately isolated from the umbilical vein collagenase eluate by a MoFlo Cell Sorter [Beckman Coulter (UK) Ltd., High Wycombe, UK]. The eluate was labeled with monoclonal antibody against CD31 (phyoerythrin-conjugated M0832, Dako UK Ltd., Ely, UK) and CD18 (FITC-conjugated FAB1730F, R\&D Systems Europe Ltd., Abingdon, UK), and cells were sorted according to CD31-positive, CD18-negative (to discriminate from leukocytes) and forward light scatter (to discriminate from platelets). The sorted EC were used without culture for extraction of mRNA only (see below).

The system for culturing EC under static or flow conditions has been described in detail elsewhere [32]. Primary cultures of HUVEC or HUAEC, or HCAEC between passages 3 and 4, were dissociated with trypsin/EDTA (Sigma) and seeded into rectangular glass capillaries (microslides, internal width $3 \mathrm{~mm}$, depth $0.3 \mathrm{~mm}$ ) which had been coated with collagen/gelatin as described previously $[31,33]$. Seeding was at a density that yielded confluent monolayers within $24 \mathrm{~h}$. After seeding, the microslides were placed into specially constructed glass dishes and attached to 
Table 1. Composition of culture media

\begin{tabular}{|c|c|c|c|c|}
\hline \multirow[t]{2}{*}{ Component } & \multicolumn{4}{|c|}{ Medium designation } \\
\hline & Basic & HUVEC & HUAEC & HCAEC \\
\hline Basal medium & $\begin{array}{l}\text { medium } \\
199\end{array}$ & $\begin{array}{l}\text { medium } \\
199\end{array}$ & SMCBM & ECBM \\
\hline Fetal calf serum, \% & - & 20 & 5 & 5 \\
\hline Human serum, \% & 20 & - & - & - \\
\hline hEGF, ng/ml & - & 1 & 0.5 & 0.1 \\
\hline hbFGF, ng/ml & - & - & 2 & 1 \\
\hline ECGS/H, \% (v/v) & - & - & - & 0.4 \\
\hline Na-heparin, U/ml & 50 & - & - & - \\
\hline Hydrocortisone, $\mu \mathrm{g} / \mathrm{ml}$ & - & - & - & 1 \\
\hline Penicillin, $\mu \mathrm{g} / \mathrm{ml}$ & - & - & 12.5 & 12.5 \\
\hline Gentamicin, $\mu \mathrm{g} / \mathrm{ml}$ & 28 & 28 & - & - \\
\hline Amphotericin, $\mu \mathrm{g} / \mathrm{ml}$ & 2.5 & 2.5 & 2.5 & 2.5 \\
\hline
\end{tabular}

Medium 199 (Medium M199 Earl's salt, 31150-022) was obtained from Invitrogen (Paisley, UK). SMCBM = Smooth muscle cell basal medium 2; ECBM = endothelial cell basal medium (both from Promocell). The additives for HUAEC and HCAEC media were supplied as kits (C39210 and C39225, respectively, Promocell): hEGF = human recombinant EGF; hbFGF = human recombinant bFGF; ECGS/H = EC growth supplement (bovine hypothalamic extract)/heparin. Other reagents were from Sigma (Poole, UK).

glass tubing which had been fused into the wall. Silicon rubber tubing (Tygon R1000, Fisher, Loughborough, UK) was connected to each external arm. The dish contained culture medium and was placed in a humidified $\mathrm{CO}_{2}$ incubator. The tubing was passed through a port in the incubator wall. The tubing from two adjacent arms (one attached to a microslide and one empty) was connected and placed into a multichannel, 8-roller pump (model 502S, Watson Marlow Ltd.), forming a continuous flow loop. The bore of the pump tubing and pump speed were chosen to deliver a flow rate $(7.76 \mathrm{ml} / \mathrm{min})$ that produced a wall shear stress of 2.0 $\mathrm{Pa}\left(20 \mathrm{dyn} / \mathrm{cm}^{2}\right)$ in the microslide. The pump and external tubing were enclosed in a Perspex box, which was thermostatically regulated at $37^{\circ} \mathrm{C}$. The tubing from a separate microslide in each dish was connected to a separate pump. This pumped a small amount of medium through the microslide for 30 s once an hour, to enable prolonged growth under our standard, 'static' conditions [31, 33]. Several separate dishes could be cultured in parallel at any time, so that HUVEC and HUAEC or HCAEC could be compared directly, or cells could be compared in different media. Each experiment with HUVEC or HUAEC used cells from a different donor. A total of 4 separate isolates of HCAEC from single donors (supplier's information) were used in the study.

There were 2 main culture protocols, as follows: (1) EC were cultured under static conditions for $48 \mathrm{~h}$ and then TNF- $\alpha$ (1, 10 or $100 \mathrm{U} / \mathrm{ml})$ or IL-1 $\left(5 \times 10^{-10} \mathrm{~g} / \mathrm{ml}\right)$ was added for a further $4 \mathrm{~h}$ under static conditions, and (2) HUVEC were cultured under static conditions for $24 \mathrm{~h}$ and then exposed to shear stress of 2.0 Pa for $24 \mathrm{~h}$, after which TNF- $\alpha$ or IL-1 $\beta$ was added and flow continued for $4 \mathrm{~h}$. Paired, control, static microslides in each dish were exposed to identical recirculated medium and cytokines for the same periods.

\section{Isolation of Neutrophils and Analysis of Adhesion and Migration under Flow}

Blood was collected from healthy volunteers into $\mathrm{K}_{2}$ EDTA (Sarstedt Ltd., Leicester, UK). Neutrophils were isolated as described previously [33] and suspended in phosphate-buffered saline (PBS) containing $1 \mathrm{mM} \mathrm{Ca}^{2+}, 0.5 \mathrm{mM} \mathrm{Mg}^{2+}$ and $0.15 \%$ culturetested bovine serum albumin (Sigma) (PBS/BSA) at $10^{6} \mathrm{cells} / \mathrm{ml}$.

Adhesion assays were performed as previously described [33, 34]. Microslides containing confluent EC were viewed by phase contrast video microscopy during perfusion of a 4-min bolus of neutrophils and subsequent washout with PBS/BSA, all at a flow rate equivalent to a wall shear stress of $0.1 \mathrm{~Pa}$. Videomicroscopic recordings were analysed off-line using a computerised image analysis system (ImagePro, DataCell Ltd., Finchampstead, UK). Adherent cells were easily distinguished from non-adherent cells, which were visible only as faint streaks. In general, the following types of behaviour of the neutrophils could be observed: (1) steady, slow rolling over the surface (velocity approx. 5-10 $\mu \mathrm{m} \cdot \mathrm{s}^{-1}$ ); (2) stable 'stationary' adhesion on the surface (phase bright and stationary or migrating slowly), and (3) transmigration (phase dark and migrating at approx. $10-15 \mu \mathrm{m} \cdot \mathrm{min}^{-1}$ under the EC monolayer) [35]. After bolus perfusion and a 5-min washout, the number of adherent neutrophils in each category (rolling adherent, stationary or transmigrated) was counted, and the total corrected per square millimeter per $10^{6}$ cells perfused.

\section{Evaluation of Gene Expression by Reverse Transcriptase PCR} or Quantitative Real-Time PCR

RNA was extracted from EC within microslides or from suspended EC using an RNeasy Mini Kit (Qiagen Ltd., Crawley, UK). Reverse transcription of single-stranded cDNA and reverse transcriptase (RT)-PCR for $\beta$-actin and E-selectin were conducted as described elsewhere [16]. Amplified products were analysed on a $2 \%$ agarose gel containing ethidium bromide. Kruppel-like factor-2 (KLF2), endothelial nitric oxide synthase, IL-8, growth-related oncogen- $\alpha$, epithelial neutrophil-activating peptide 78 , ICAM-1 and VCAM-1 mRNA were analyzed by quantitative realtime PCR (qPCR) using a Quanti-Tect ${ }^{\mathrm{TM}}$ probe RT-PCR kit according to the manufacturer's instructions (Qiagen). Primers were bought as Taqman Gene Expression Assays (Applied Biosystems, Warrington, UK). Samples were amplified using the 7500 HT Real-Time PCR machine and analysed using the software package SDS 2.2 (Applied Biosystems). Data were initially expressed as relative expression units compared to mRNA for $18 \mathrm{~S}$ in the same samples.

\section{Statistical Analysis}

Comparisons of different culture conditions (e.g. sheared vs. static culture) were performed by comparing the ratio of sheared to static culture to 1 by Student's t test. Analysis of variance (ANOVA) was used to test whether the changes in expression of a panel of genes when freshly isolated cells were established in static culture were different from the changes when static cultures were exposed to shear stress. 


\section{Results}

Responses to Cytokines of Different EC Cultured under Static Conditions in Different Media

We previously characterised in detail the dose-dependent responses of HUVEC to TNF- $\alpha$ or IL-1 $\beta$, based on the levels of adhesion and migration of flowing neutrophils $[13,16,34]$. Here, we aimed initially to compare responses of different EC (HUVEC, HUAEC, HCAEC) and examine any effects of different culture media used for these cells. Initially, HUVEC and HUAEC were cultured successfully in a relatively simple medium which contained human serum and no added growth factors ('basic' medium; table 1). Both cell types supported adhesion of many flowing neutrophils after stimulation with 10 or $100 \mathrm{U} / \mathrm{ml} \mathrm{TNF}-\alpha$, but there was a tendency toward less efficient transendothelial migration of neutrophils for HUAEC (data not shown). Since human serum was expensive and showed inter-batch growth variation, we switched to medium in which it was replaced by fetal calf serum and EGF ('HUVEC' medium; table 1). There was good growth of HUVEC and efficient recruitment of neutrophils after TNF- $\alpha$ stimulation, but HUAEC grew very poorly in this medium and we did not succeed in passaging them into microslides for the flow-based adhesion assay. HUAEC were then grown successfully in a commercially available medium recommended for smooth muscle cells, which contained bFGF as well as EGF and also dexamethasone. This medium was designated 'HUAEC' medium. HUVEC also grew well in this medium, but both HUVEC and HUAEC showed relatively weak responses to $100 \mathrm{U} / \mathrm{ml} \mathrm{TNF}-\alpha$ and neutrophil transmigration was almost absent. Dexamethasone has been shown by others to inhibit neutrophil migration through cytokine-stimulated EC [36], and when it was removed, cell growth appeared unaltered, but the response to TNF- $\alpha$ increased. HCAEC grew well in the supplier's recommended 'HCAEC' medium, which contained EGF, EC growth supplement/heparin and hydrocortisone (table 1), as did HUVEC.

Figure 1 summarises comparative studies of HUVEC in different media and of HUAEC and HCAEC in their 'own' media. The total numbers of adherent neutrophils and the numbers of neutrophils that migrated through the endothelial monolayer after stimulation with TNF- $\alpha$ or IL-1 $\beta$ are shown. HUVEC supported mainly rolling adhesion at $1 \mathrm{U} / \mathrm{ml} \mathrm{TNF}-\alpha$ and a greater level of adhesion at $100 \mathrm{U} / \mathrm{ml}$, with about $50 \%$ of adherent cells transmigrating. Results were similar for the 3 media tested. HUAEC tended to support lower levels of adhesion than
HUVEC, and a lower proportion of adherent neutrophils transmigrated. However, neutrophil adhesion and transmigration on HCAEC were similar to those on HUVEC.

Studies of responses to IL-1 $\beta$ (at a concentration found to be optimal in an earlier study [13]) were performed for the same cells in the same media (fig. 1b). Levels of adhesion were high, and transendothelial migration was efficient ( $\geq 80 \%$ of adherent cells) for all cells in all media, and there were no consistent effects of these variables. Thus, in summary, all types of EC were able to support effective adhesion and migration of neutrophils after stimulation with TNF- $\alpha$ or IL-1 $\beta$, and the effects of different media on these responses were small (except for removal of dexamethasone).

\section{Effects of Shear Conditioning on Responses to}

Cytokines in Different EC in Different Media

We have previously shown that conditioning of HUVEC with shear stress modifies the EC response to TNF- $\alpha$ in a manner that depends on the magnitude and duration of the stress applied [16]. After culture for $24 \mathrm{~h}$ at $2.0 \mathrm{~Pa}$, adhesion of neutrophils induced by TNF- $\alpha$ was nearly ablated, and the expression of inflammatory genes, including the major neutrophil capture receptor E-selectin, was markedly reduced. However, the response of HUVEC to IL-1 $\beta$ was not affected [13]. Here, we compared the responses to TNF- $\alpha$ and IL-1 $\beta$ by HUVEC, HUAEC and HCAEC after conditioning for $24 \mathrm{~h}$ at $2.0 \mathrm{~Pa}$. Each EC type was cultured in its own medium (HUVEC, HUAEC and HCAEC medium, respectively). As previously, we found that the response of HUVEC to TNF- $\alpha$ was greatly reduced, as assessed by neutrophil adhesion, but not the response to IL-1 $\beta$ (fig. 2a). However, for HUAEC and HCAEC, responses to both cytokines were greatly reduced after shear conditioning (fig. 2b, c). Analysis of mRNA for E-selectin showed changes commensurate with the patterns of adhesion (fig. 3); increases induced by TNF- $\alpha$ and IL- $1 \beta$ were suppressed in HUAEC and HCAEC by shear stress, but only the response to TNF- $\alpha$ was suppressed in HUVEC. Since we did not analyse mRNA for HCAEC after stimulation with IL-1 $\beta$ in this first series of experiments, we carried out an additional analysis for these cells using qPCR. This confirmed a marked up-regulation of the expression of E-selectin after stimulation with TNF- $\alpha$ or IL-1 $\beta$ (approx. 8- and 5-fold, respectively) and effective inhibition of up-regulation after shear conditioning (not shown). These analyses in the cells' own media showed that mRNA levels for E-selectin correlated with the functional adhe- 
Fig. 1. Adhesion and migration of neutrophils on different types of EC cultured in different media and treated for $4 \mathrm{~h}$ with TNF- $\alpha(\mathbf{a} ; 1$ or $100 \mathrm{U} / \mathrm{ml})$ or IL-1 $\beta$ (b; $5 \times$ $\left.10^{-10} \mathrm{~g} / \mathrm{ml}\right)$. Total adhesion and the number of neutrophils that transmigrated through the EC are shown, both normalised per square millimeter per $10^{6}$ cells perfused. The compositions of the different media are shown in table 1. Data are means \pm SEM from 3 or more experiments.
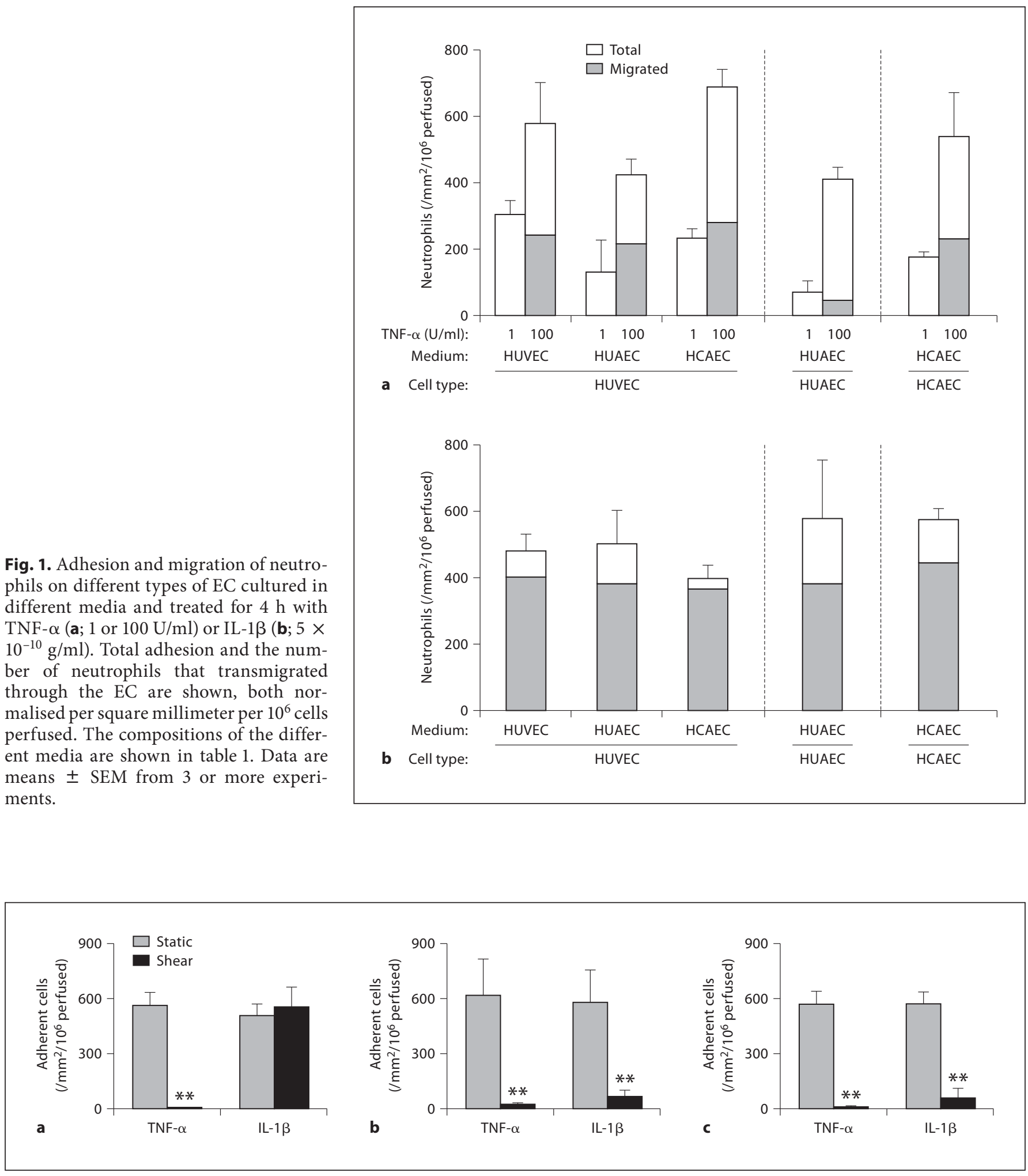

Fig. 2. Effect of shear conditioning (24 h at 2.0 Pa) of HUVEC (a), HUAEC (b) and HCAEC (c) on the adhesion of neutrophils after the EC were treated for $4 \mathrm{~h}$ with TNF- $\alpha(100 \mathrm{U} / \mathrm{ml})$ or IL-1 $\beta(5 \times$ $\left.10^{-10} \mathrm{~g} / \mathrm{ml}\right)$. Culture media were $\operatorname{HUVEC}(\mathbf{a}), \operatorname{HUAEC}(\mathbf{b})$ and
HCAEC (c). Data are means \pm SEM from 3 or more experiments. ** $\mathrm{p}<0.01$ for the ratio of shear to static culture $<1$ (Student's $t$ test). 


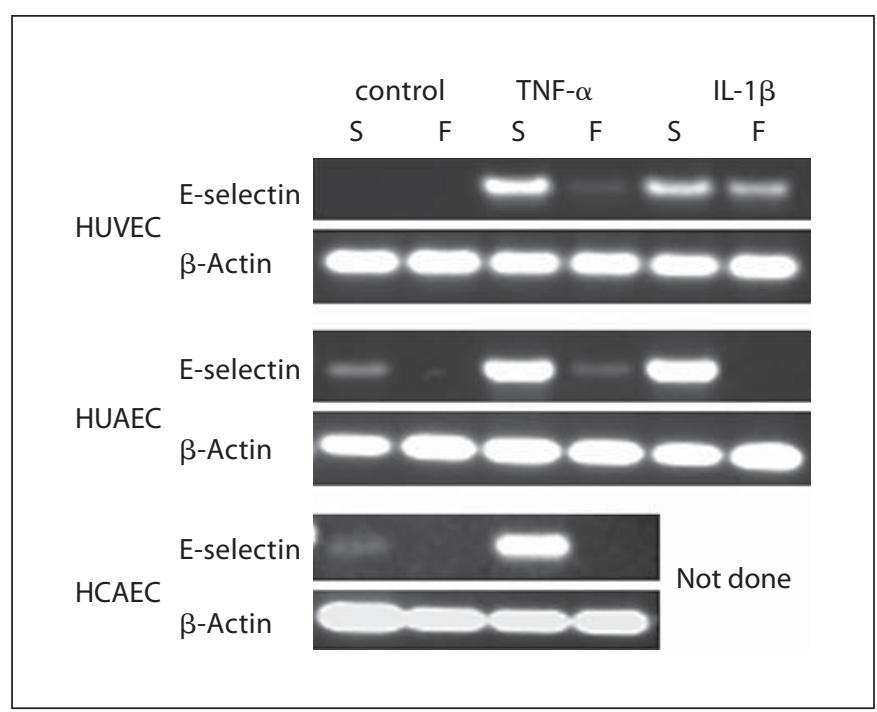

Fig. 3. Effect of shear conditioning of different EC on their expression of E-selectin without cytokine treatment (control) or after treatment with TNF- $\alpha(100 \mathrm{U} / \mathrm{ml})$ or IL-1 $\beta\left(5 \times 10^{-10} \mathrm{~g} / \mathrm{ml}\right)$. Ethidium bromide gels are shown for DNA amplified by RT-PCR from mRNA extracted from EC which were cultured for $26 \mathrm{~h}$ under static conditions ( $\mathrm{S}$ ) or exposed to flow (F; shear stress $=2.0$ $\mathrm{Pa}$ ), with cytokines added for the last $2 \mathrm{~h}$. Actin is shown as a loading control unmodified by treatment. The results are representative of 2 or more experiments.

sion responses; up-regulation of E-selectin expression by TNF- $\alpha$ was suppressed by shear stress in all cell types, but suppression of expression in response to IL-1 $\beta$ was evident in HUAEC and HCAEC but not HUVEC.

Given that the cells had been cultured in different media, we wondered if differences in the modulation of responses to IL-1 $\beta$ by shear stress were due to different stable phenotypes of the cells or to the culture conditions. Although there were a number of differences between the media, a common ingredient of the HUAEC and HCAEC media that was lacking in the HUVEC medium was bFGF (table 1). Therefore, we compared HUVEC cultured in HUVEC or HUAEC medium, and also with bFGF removed from the HUAEC medium or added to the HUVEC medium. When HUVEC were cultured in HUAEC medium, shear conditioning caused a reduction in the response to IL-1 $\beta$ similar to that originally seen in HUAEC (fig. 4). When bFGF was left out of the HUAEC medium, shear conditioning was no longer effective; when bFGF was added to the HUVEC medium, shear conditioning did significantly reduce the response of HUVEC to IL- $1 \beta$, albeit to a lesser degree than that seen in HUAEC medium (fig. 4). Extending this approach, we next compared

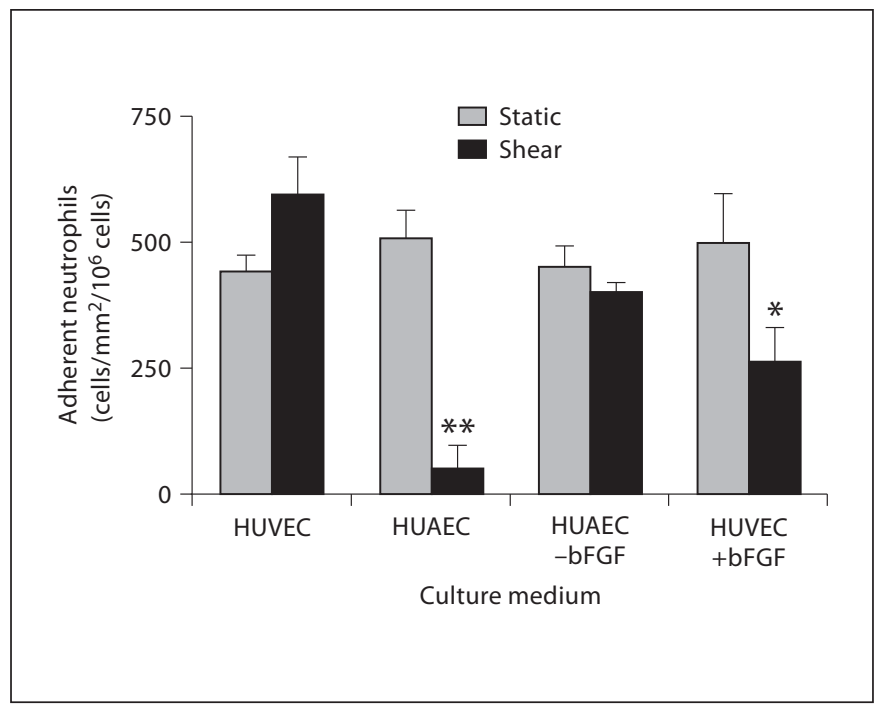

Fig. 4. Effect of shear conditioning $(24 \mathrm{~h}$ at $2.0 \mathrm{~Pa})$ on the adhesion of neutrophils to HUVEC grown in different media and treated for $4 \mathrm{~h}$ with IL-1 $\beta\left(5 \times 10^{-10} \mathrm{~g} / \mathrm{ml}\right)$. HUVEC were cultured in HUVEC or HUAEC medium, or in HUAEC medium with bFGF taken out, or HUVEC medium with bFGF added. Data are means \pm SEM from 3 or more experiments in each case. ${ }^{*} \mathrm{p}<0.05$, ** $\mathrm{p}<0.01$ for the ratio of shear to static culture compared to 1 (Student's t test).

the responses of the 3 different types of $\mathrm{EC}$ in the same media, i.e. HUAEC medium with or without bFGF. The trends were the same for each type of EC; shear conditioning reduced the response to IL-1 $\beta$ in the complete medium, but when bFGF was removed, the effect of the shear stress was reduced and no longer significant (fig. 5).

Thus, differences between the different EC when cultured in the same media were not great. Indeed, when we cultured HCAEC in HUVEC medium, with shear conditioning, the response to IL- $1 \beta$ was absent, as might be expected (adhesion with shear conditioning averaged $106 \%$ of adhesion without shear conditioning, mean of 2 experiments). However, when HUVEC were cultured in HCAEC medium (which contained bFGF), they did not show shear responsiveness to IL- $1 \beta$ stimulation (adhesion with shear conditioning averaged $87 \%$ of adhesion without shear conditioning, mean of 3 experiments). The shear responsiveness of HUVEC to TNF- $\alpha$ stimulation was maintained in this medium (data not shown). The above results clearly indicate that culture medium ingredients, and particularly bFGF, can modify the effects of shear stress on EC as judged by the subsequent response 
Fig. 5. Effect of shear conditioning ( $24 \mathrm{~h}$ at $2.0 \mathrm{~Pa}$ ) on the adhesion of neutrophils to different EC grown in HUAEC medium (which includes bFGF) or HUAEC medium without bFGF and treated for $4 \mathrm{~h}$ with IL-1 $\beta\left(5 \times 10^{-10} \mathrm{~g} / \mathrm{ml}\right)$. Data are means \pm SEM from 3 or more experiments in each case. ${ }^{*} \mathrm{p}<0.05,{ }^{* *} \mathrm{p}<0.01$ for the ratio of shear to static culture compared to 1 (Student's t test).

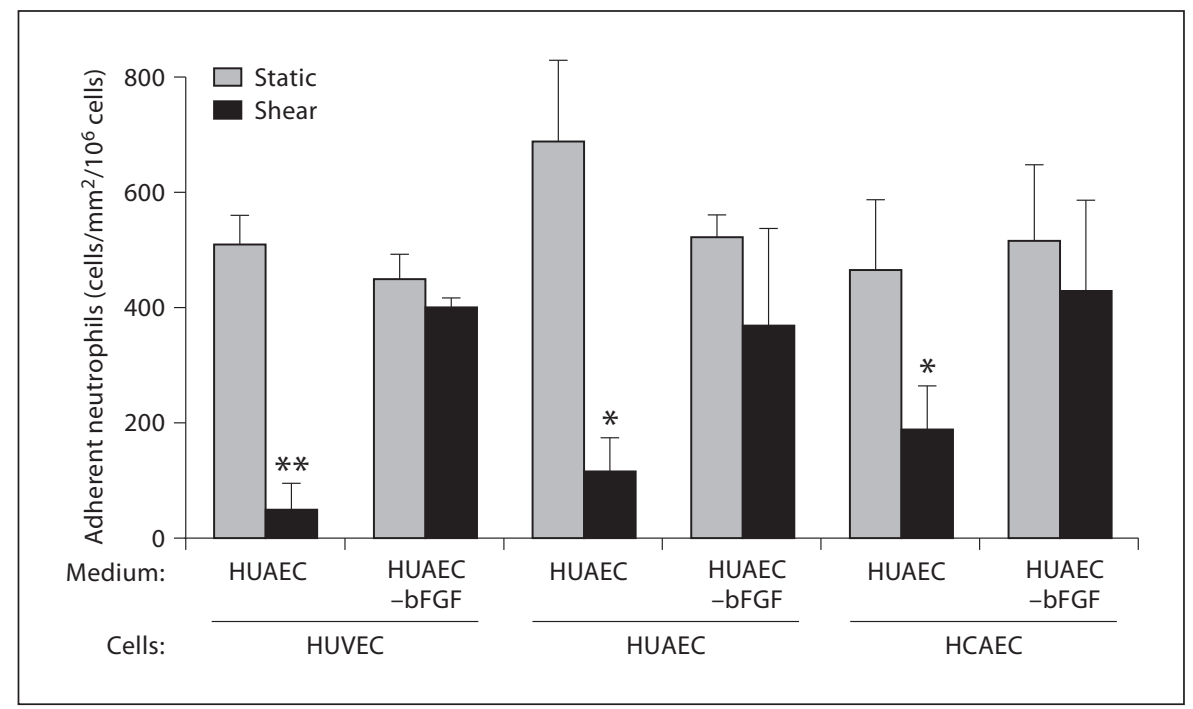

to IL-1 $\beta$ (although this did not apply to the response to TNF- $\alpha$, which was universally down-regulated). Nevertheless, there are also some differences between the responses of the different EC in specific media, which suggests that the cellular origin can have an effect, as well as culture conditions.

Changes in Gene Expression during Culture and upon Exposure to Shear Stress

The above findings suggest that $\mathrm{EC}$ responses depend upon exposure to shear stress and the local growth environment in a complex and potentially interacting manner. To test this further, we analysed the expression of a group of genes linked to shear conditioning and/or inflammatory responses in HUVEC immediately after removal from the cord, after 5 days in standard static culture and then after $24 \mathrm{~h}$ of exposure to shear stress. Genes previously reported to be affected by shear stress in vitro, the transcription factor KLF2 and endothelial nitric oxide synthase, showed a reduction in mRNA expression after isolation and then recovered upon exposure to shear (fig. 6). However, other genes linked to inflammation (CXC chemokines, VCAM-1, ICAM-1) increased after isolation, but did not consistently decrease again when exposed to shear (fig. 6). These results verify that while shear stress is a major factor in the regulation of genes (and hence cell phenotype), other factors, which, for example, may be present in the intact cord but not in cell culture, contribute to local environmental control of the phenotype. They also show the genomic pliability of EC.

Modulation of Endothelial Cell Phenotype
We also examined whether the shear sensitivity of KLF2 was evident for each of the different types of EC, when cultured in HUAEC medium with and without bFGF. KLF2 was unregulated by shear for each cell type, and the presence or absence of bFGF had no consistent effect. The shear-induced increase was lower for the HCAEC, but these cells showed higher initial expression of this gene relative to $18 \mathrm{~S}$ (not shown). Thus, although bFGF modulated the shear conditioning of the response to IL-1 3 , in respect to KLF2, the cells responded similarly to shear in the presence or absence of bFGF. These results also suggest that modulation of the response to IL$1 \beta$ was not directly linked to the level of KLF2 expression.

\section{Discussion}

We have found that human EC from several different vessels can all support efficient adhesion and migration of flowing neutrophils after stimulation with TNF- $\alpha$ or IL-1 $\beta$. In addition, they all showed a reduction of the response to TNF- $\alpha$ when they were conditioned by shear stress instead of being cultured under static conditions. In general, the response to IL- $1 \beta$ was also reduced by shear conditioning, but this reduction was itself modulated by the medium used for culture and particularly bFGF. Primary HUVEC cultured for 5 days had a different phenotype from cells freshly isolated from the umbilical vein, as judged by expression of a panel of inflammation-related genes, and this was only partly reversed

J Vasc Res 2010;47:451-461 


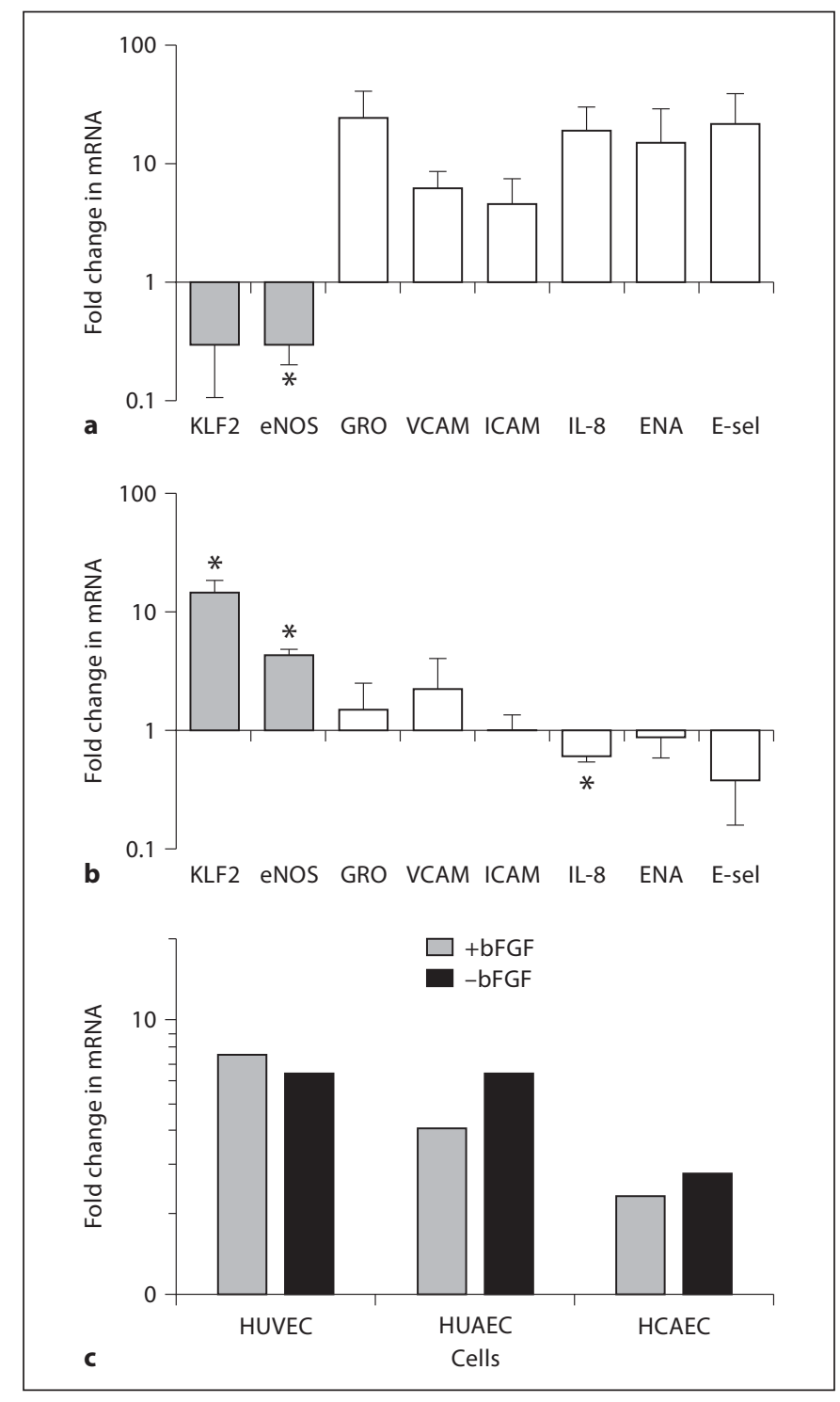

Fig. 6. Effects of initial establishment of static endothelial cultures and subsequent exposure to shear stress (2.0 $\mathrm{Pa}$ for $24 \mathrm{~h}$ ) on the expression of genes relevant to inflammatory responses. a RNA was extracted from HUVEC immediately after isolation and after culture for 5 days under static conditions; the fold changes in RNA for various genes for static cultures/freshly isolated cells are shown. b RNA was extracted from HUVEC after culture for 5 days followed by $24 \mathrm{~h}$ of static culture or under shear stress; the fold changes in RNA for shear-treated/static cells are shown. c RNA was extracted from HUVEC, HUAEC or HCAEC after culture in HUAEC medium with or without bFGF, for static cultures or cultures exposed to shear stress for $24 \mathrm{~h}$; the fold changes in RNA for KLF2 for shear-treated/static cells are shown. All RNA levels were first normalised relative to $18 \mathrm{~S}$ measured in the same sample using qPCR. Data are means \pm SEM from 3 independent comparisons of each type, except in c, where the means of 2 comparisons are shown. ANOVA of data in $\mathbf{a}$ and $\mathbf{b}$ showed that the overall changes in gene expression in a differed from those in $\mathbf{b}(\mathrm{p}<0.05) .{ }^{*} \mathrm{p}<$ 0.05 for the fold change compared to 1 (Student's $t$ test). when the cultured cells were exposed to flow. Thus, EC are pliable in their phenotypes. When studied in vitro, they may respond quite differently compared to in vivo, and their responses depend on culture conditions as much as their source. These results add weight to the concept that variations in shear stress as well as stromal factors will contribute to differences in the characteristics of EC in different locations in the vasculature.

Differences between the functional responses of the different EC cultured under 'standard' conditions were not great. All cells supported highly efficient adhesion and transmigration when stimulated with IL-1 $\beta$. After treatment with TNF- $\alpha$, HUAEC showed a tendency to support lower levels of migration in adherent cells than the other EC. A previous report indicated that HUAEC responded much less strongly than HUVEC to TNF- $\alpha$ and, for example, did not up-regulate expression of E-selectin or adhesion of a monocytic cell line [26]. We did not reproduce this finding, possibly because the earlier study used cells from passage 5 and different culture media. Others have found similar adhesion of T cells to cytokine-treated human dermal microvascular EC and HUVEC [25]. Adhesion of various types of leukocytes to SVEC was similar to HUVEC after cytokine treatment, but there was a markedly lower response for HUVEC when oxidised low-density lipoprotein was used as the stimulant [29]. While the SVEC and HUVEC were cultured in different media in that study, our study found relatively little effect of changes in media on the responses of static cultures of any EC. The only marked effect was from dexamethasone, originally contained in the HUAEC medium, which reduced the response to TNF- $\alpha$ and was subsequently removed. Hydrocortisone was included in the HCAEC medium, but the responses of HUVEC to TNF- $\alpha$ or IL-1 $\beta$ were similar when cultured in HCAEC and HUVEC medium (where hydrocortisone was absent). We previously found that $1 \mu \mathrm{g} / \mathrm{ml}$ hydrocortisone had an inhibitory effect on HUVEC at a low dose of TNF$\alpha(1 \mathrm{U} / \mathrm{ml})$ but not at a dose of $100 \mathrm{U} / \mathrm{ml}$ [37]. It also strongly inhibited the inflammatory effects of synovial fibroblasts on HUVEC, which was linked with a reduction in the release of IL-6 in these co-cultures [38]. In our hands, HUVEC undergo repeated passage and long-term culture more successfully in the presence of hydrocortisone, although its use is not necessary at the first passage as used here. Overall, it seems that variations in culture media are more likely to affect responses to lower levels of stimulation than responses to powerful stimulation. However, they can clearly modulate responses to other environmental factors such as shear stress. 
Given the wide range of functions of EC that have been shown to be modulated by shear stress, it may not be surprising that all EC tested here responded to changes in this factor. Unexpectedly, shear modulation of the response to IL- $1 \beta$ depended on the culture medium and in particular on the presence of bFGF. We are not aware of previous studies showing modulation of shear sensitivity in EC by other culture conditions, although the substrate on which cells are grown can influence shear-induced signalling [39]. Previous studies by others indicated that bFGF itself decreased the adhesion of monocytes to TNF$\alpha$ - or IL-1 $\beta$-treated HUVEC and chemotaxis through HUVEC [40]. In the present study, bFGF had no discernible effect on the adhesion or migration of neutrophils on HUVEC under comparable static culture conditions, but it was used at a higher dose in the earlier study (10 vs. $2 \mathrm{ng} / \mathrm{ml}$ ). Conversely, acute injection of bFGF increased both monocyte and neutrophil recruitment into skin induced by co-injection of TNF- $\alpha$ [41]. Initial adhesion and migration would have been through shear-conditioned EC in vivo, but this effect of bFGF is clearly different to that seen with prolonged pre-treatment in vitro. The implication remains that in vivo phenotypes or behaviour of EC depend on a combination of local factors, and that in vitro responses of $\mathrm{EC}$ depend on culture conditions as well as their source. The different EC investigated here were all responsive to TNF- $\alpha$ or IL-1 $\beta$, with only small differences in the numbers of neutrophils adhering or transmigrating. All showed strong down-regulation of the response to TNF- $\alpha$ by shear stress. When tested in the same media, all showed a shear-dependent reduction in the response to IL- $1 \beta$ when bFGF was present, and a much lower (and non-significant) effect of shear stress when bFGF was absent. Nevertheless, each EC type showed up-regulation of expression of the transcription factor KLF2 in the presence or absence of bFGF. There was a difference in the shear response between HUVEC and HCAEC when cultured in the HCAEC medium, and minor differences in the degrees of shear modulation for the different EC when tested with or without bFGF. In a recent study, SVEC and HCAEC were cultured under static conditions, low shear stress or highly pulsatile flow in the same medium [42]. While shear tended to reduce adhesion molecule expression in response to TNF- $\alpha$ for HCAEC, the opposite was seen for SVEC, indicating that similarities in the shear response observed here may not be shared by all EC.

The foregoing has implications for the interpretation or design of in vitro studies of endothelial behaviour. Although the ability of EC to support recruitment of neu- trophils might not be considered a primary function of any of the original vessels studied here, all did so effectively when cultured under static conditions. The reduction in sensitivity to cytokines after conditioning by flow may resemble the original responses of these cells in vivo more closely. Reproduction of responses seen in vivo might thus be said to require imposition of shear. However, although we found clear changes in gene expression in HUVEC during establishment of static cultures, re-application of shear only partly 'recovered' the original in vivo pattern. Clearly other environmental factors also affect endothelial behaviour, practically demonstrated here by the effects of growth factors used during culture. One might conclude that given the pliability of the endothelial phenotype, the origin of the cells used for functional studies in vitro is less important than the culture conditions, especially when the presence or absence of flow is included. In general, maintenance of differences between EC might depend on exposure to an environment mimicking that found in vivo. For instance, studies of EC from liver sinusoids show maintenance of a specific adhesive phenotype, but this occurs in medium specifically developed to support culture of these specialised cells and may normally arise from the influence of local stromal cells $[28,43]$. Nevertheless, there are some notable differences in the behaviour of EC from different sources, e.g. related to leukocyte recruitment, even when tested under the same conditions [42, 44]. Thus, while EC behaviour is powerfully modulated by culture conditions, some imprinted differences in endothelial phenotype may be retained in vitro. This makes it difficult to predict comparative responses of $\mathrm{EC}$ from different origins a priori, even when conditions are matched. If one wishes to investigate organ-specific processes, it might be wise to analyse whether expression of functional receptors specific to that organ is maintained in culture and, for example, whether it differs from HUVEC, which might be considered something of a 'standard'. For studies of more 'generic' processes, our results suggest that the choice of endothelial source is less important than the culture conditions applied and, for example, the availability of lowpassage primary cells.

From the physiological perspective, our results indicate that site-dependent responses to inflammatory stimuli may arise from differences in flow conditions and stromal growth conditions in local vessels. In long-term cultures of HUVEC, deposition of basement membrane was associated with changes in neutrophil migration induced by TNF- $\alpha$ [45], and changes in matrix proteins may also influence shear responses of EC [39]. We re- 
cently found that different types of fibroblasts had quite different effects on $\mathrm{T}$ cell recruitment [10], and, again, interactions between EC and stromal cells (smooth muscle cells in this case) may themselves be modulated by shear stress [9]. It is likely that other functional responses in addition to leukocyte adhesion and migration are regulated by the local microenvironment, and elucidation of how this comes about will be important in order to understand normal and pathological responses to injury and infection.

\section{Acknowledgements}

This work was supported by The British Heart Foundation (grant number RCAZ12281). Umbilical cords were collected with the assistance of the Birmingham Women's Health Care NHS Trust.

\section{References}

$\checkmark 1$ Davies PF: Flow-mediated endothelial mechanotransduction. Physiol Rev 1995;75:519560.

2 Chien S, Li S, Shyy YJ: Effects of mechanical forces on signal transduction and gene expression in endothelial cells. Hypertension 1998;31:162-169.

$\checkmark 3$ Wasserman SM, Topper JN: Adaptation of the endothelium to fluid flow: in vitro analyses of gene expression and in vivo implications. Vasc Med 2004;9:35-45.

4 Lipowsky HH: Shear stress in the circulation; in Bevan J, Kaley G (eds): Flow Dependent Regulation of Vascular Function. New York, Oxford University Press, 1985, pp 2845.

$\checkmark 5$ Reneman RS, Arts T, Hoeks AP: Wall shear stress - an important determinant of endothelial cell function and structure - in the arterial system in vivo. Discrepancies with theory. J Vasc Res 2006;43:251-269.

$\checkmark 6$ Aird WC: Endothelial cell heterogeneity. Crit Care Med 2003;31:S221-S230.

7 Nash GB, Buckley CD, Rainger GE: The local physicochemical environment conditions the proinflammatory response of endothelial cells and thus modulates leukocyte recruitment. FEBS Lett 2004;569:13-17.

-8 Rainger GE, Nash GB: Cellular pathology of atherosclerosis: smooth muscle cells prime cocultured endothelial cells for enhanced leukocyte adhesion. Circ Res 2001;88:615622.

>9 Chiu JJ, Chen LJ, Lee PL, Lee CI, Lo LW, Usami S, Chien S: Shear stress inhibits adhesion molecule expression in vascular endothelial cells induced by coculture with smooth muscle cells. Blood 2003;101:2667-2674.

10 McGettrick HM, Smith E, Filer A, Kissane S, Salmon M, Buckley CD, Rainger GE, Nash GB: Fibroblasts from different sites may promote or inhibit recruitment of flowing lymphocytes by endothelial cells. Eur J Immunol 2009;39:113-125.
11 Springer TA: Traffic signals on endothelium for lymphocyte recirculation and leukocyte emigration. Annu Rev Physiol 1995;57:827872 .

12 Cines DB, Pollak ES, Buck CA, Loscalzo J, Zimmerman GA, McEver RP, Pober JS, Wick TM, Konkle BA, Schwartz BS, Barnathan ES, McCrae KR, Hug BA, Schmidt AM, Stern DM: Endothelial cells in physiology and in the pathophysiology of vascular disorders. Blood 1998;91:3527-3561.

13 Sheikh S, Rainger GE, Gale Z, Luu NT, Rahman M, Nash GB: Differing mechanisms of leukocyte recruitment and sensitivity to conditioning by shear stress for endothelial cells treated with tumour necrosis factor- $\alpha$ or interleukin-1 $\beta$. Br J Pharmacol 2005;145: 1052-1061.

14 Surapisitchat J, Hoefen RJ, Pi X, Yoshizumi M, Yan C, Berk BC: Fluid shear stress inhibits TNF- $\alpha$ activation of JNK but not ERK1/2 or p38 in human umbilical vein endothelial cells: inhibitory crosstalk among MAPK family members. Proc Natl Acad Sci USA 2001;98:6476-6481.

15 Chiu JJ, Lee PL, Lee CI, Chen LJ, Chen CN, Ko YC, Lien SC: Shear stress attenuates tumor necrosis factor-alpha-induced monocyte chemotactic protein-1 expressions in endothelial cells. Chin J Physiol 2002;45: 169-176.

-16 Sheikh S, Rainger GE, Gale Z, Rahman M, Nash GB: Exposure to fluid shear stress modulates the ability of endothelial cells to recruit neutrophils in response to tumor necrosis factor-alpha: a basis for local variations in vascular sensitivity to inflammation. Blood 2003;102:2828-2834.

17 Chiu JJ, Lee PL, Chen CN, Lee CI, Chang SF, Chen LJ, Lien SC, Ko YC, Usami S, Chien S: Shear stress increases ICAM-1 and decreases VCAM-1 and E-selectin expressions induced by tumor necrosis factor-[alpha] in endothelial cells. Arterioscler Thromb Vasc Biol 2004;24:73-79.
-18 Yamawaki H, Lehoux S, Berk BC: Chronic physiological shear stress inhibits tumor necrosis factor-induced proinflammatory responses in rabbit aorta perfused ex vivo. Circulation 2003;108:1619-1625.

19 Atherton A, Born GV: Quantitative investigations of the adhesiveness of circulating polymorphonuclear leucocytes to blood vessel walls. J Physiol 1972;222:447-474.

20 Thurston G, Baluk P, McDonald DM: Determinants of endothelial cell phenotype in venules. Microcirculation 2000;7:67-80.

21 Petzelbauer P, Bender JR, Wilson J, Pober JS: Heterogeneity of dermal microvascular endothelial cell antigen expression and cytokine responsiveness in situ and in cell culture. J Immunol 1993;151:5062-5072.

-22 Mizgerd JP, Kubo H, Kutkoski GJ, Bhagwan SD, Scharffetter-Kochanek K, Beaudet AL, Doerschuk CM: Neutrophil emigration in the skin, lungs and peritoneum: different requirements for CD11/CD18 revealed by CD18-deficient mice. J Exp Med 1997;186: 1357-1364.

23 Doerschuk CM: Mechanisms of leukocyte sequestration in inflamed lungs. Microcirculation 2001;8:71-88.

24 Lee WY, Kubes P: Leukocyte adhesion in the liver: distinct adhesion paradigm from other organs. J Hepatol 2008;48:504-512.

25 Haskard DO, Cavender D, Fleck RM, Sontheimer R, Ziff M: Human dermal microvascular endothelial cells behave like umbilical vein endothelial cells in T-cell adhesion studies. J Invest Dermatol 1987;88:340-344.

-26 Kalogeris TJ, Kevil CG, Laroux FS, Coe LL, Phifer TJ, Alexander JS: Differential monocyte adhesion and adhesion molecule expression in venous and arterial endothelial cells. Am J Physiol 1999;276:L9-L19.

27 Zouki C, Baron C, Fournier A, Filep JG: Endothelin-1 enhances neutrophil adhesion to human coronary artery endothelial cells: role of ET(A) receptors and platelet-activating factor. Br J Pharmacol 1999;127:969979. 
-28 Lalor PF, Edwards S, McNab G, Salmi M, Jalkanen S, Adams DH: Vascular adhesion protein-1 mediates adhesion and transmigration of lymphocytes on human hepatic endothelial cells. J Immunol 2002;169:983-992.

-29 Tan PH, Chan C, Xue SA, Dong R, Ananthesayanan B, Manunta M, Kerouedan C, Cheshire NJ, Wolfe JH, Haskard DO, Taylor KM, George AJ: Phenotypic and functional differences between human saphenous vein (HSVEC) and umbilical vein (HUVEC) endothelial cells. Atherosclerosis 2004;173: 171-183.

-30 Wang Q, Pfeiffer GR, Stevens T, Doerschuk CM: Lung microvascular and arterial endothelial cells differ in their responses to intercellular adhesion molecule-1 ligation. Am J Respir Crit Care Med 2002;166:872-877.

-31 Cooke BM, Usami S, Perry I, Nash GB: A simplified method for culture of endothelial cells and analysis of adhesion of blood cells under conditions of flow. Microvasc Res 1993;45:33-45.

-32 Sheikh S, Gale Z, Rainger GE, Nash GB: Methods for exposing multiple cultures of endothelial cells to different fluid shear stresses and to cytokines, for subsequent analysis of inflammatory function. J Immunol Methods 2004;288:35-46.

33 Rainger GE, Fisher A, Shearman C, Nash GB: Adhesion of flowing neutrophils to cultured endothelial cells after hypoxia and reoxygenation in vitro. Am J Physiol 1995;269: 1398-1406.
34 Bahra P, Rainger GE, Wautier JL, Luu N-T, Nash GB: Each step during transendothelial migration of flowing neutrophils is regulated by the stimulatory concentration of tumour necrosis factor-alpha. Cell Adhes Commun 1998;6:491-501.

35 Luu NT, Rainger GE, Nash GB: Kinetics of the different steps during neutrophil migration through cultured endothelial monolayers treated with tumour necrosis factor-alpha. J Vasc Res 1999;36:477-485.

36 Wheller SK, Perretti M: Dexamethasone inhibits cytokine-induced intercellular adhesion molecule-1 up-regulation on endothelial cell lines. Eur J Pharmacol 1997;331: 65-71.

37 Luu NT, Madden J, Calder PC, Grimble RF, Shearman CP, Chan T, Tull SP, Dastur N, Rainger GE, Nash GB: Comparison of the pro-inflammatory potential of monocytes from healthy adults and those with peripheral arterial disease using an in vitro culture model. Atherosclerosis 2007;193:259-268.

38 Lally F, Smith E, Filer A, Stone M, Shaw J, Nash GB, Buckley CD, Rainger GE: A novel mechanism of neutrophil recruitment in a coculture model of the rheumatoid synovium. Arthritis Rheum 2005;52:3460-3469.

-39 Orr AW, Sanders JM, Bevard M, Coleman E, Sarembock IJ, Schwartz MA: The subendothelial extracellular matrix modulates NFkappaB activation by flow: a potential role in atherosclerosis. J Cell Biol 2005;169:191202.
40 Zhang H, Issekutz AC: Down-modulation of monocyte transendothelial migration and endothelial adhesion molecule expression by fibroblast growth factor: reversal by the antiangiogenic agent SU6668. Am J Pathol 2002; 160:2219-2230.

41 Zittermann SI, Issekutz AC: Endothelial growth factors VEGF and bFGF differentially enhance monocyte and neutrophil recruitment to inflammation. J Leukoc Biol 2006;80:247-257.

42 Methe H, Balcells M, Alegret MC, Santacana M, Molins B, Hamik A, Jain MK, Edelman ER: Vascular bed origin dictates flow pattern regulation of endothelial adhesion molecule expression. Am J Physiol 2007;292:H2167H2175.

43 Edwards S, Lalor PF, Nash GB, Rainger GE, Adams DH: Lymphocyte traffic through sinusoidal endothelial cells is regulated by hepatocytes. Hepatology 2005;41:451-459.

44 Lim YC, Garcia-Cardena G, Allport JR, Zervoglos M, Connolly AJ, Gimbrone MA Jr, Luscinskas FW: Heterogeneity of endothelial cells from different organ sites in T-cell subset recruitment. Am J Pathol 2003;162: 1591-1601.

45 Butler LM, Rainger GE, Rahman M, Nash GB: Prolonged culture of endothelial cells and deposition of basement membrane modify the recruitment of neutrophils. Exp Cell Res 2005;310:22-32. 